\title{
Incidence, Risk Factors, and Outcomes of Patients with COVID-19-Associated Pulmonary Aspergillosis (CAPA) in Intensive Care Units: A Systematic Review and Meta-Analysis Of 29 Cohort Studies
}

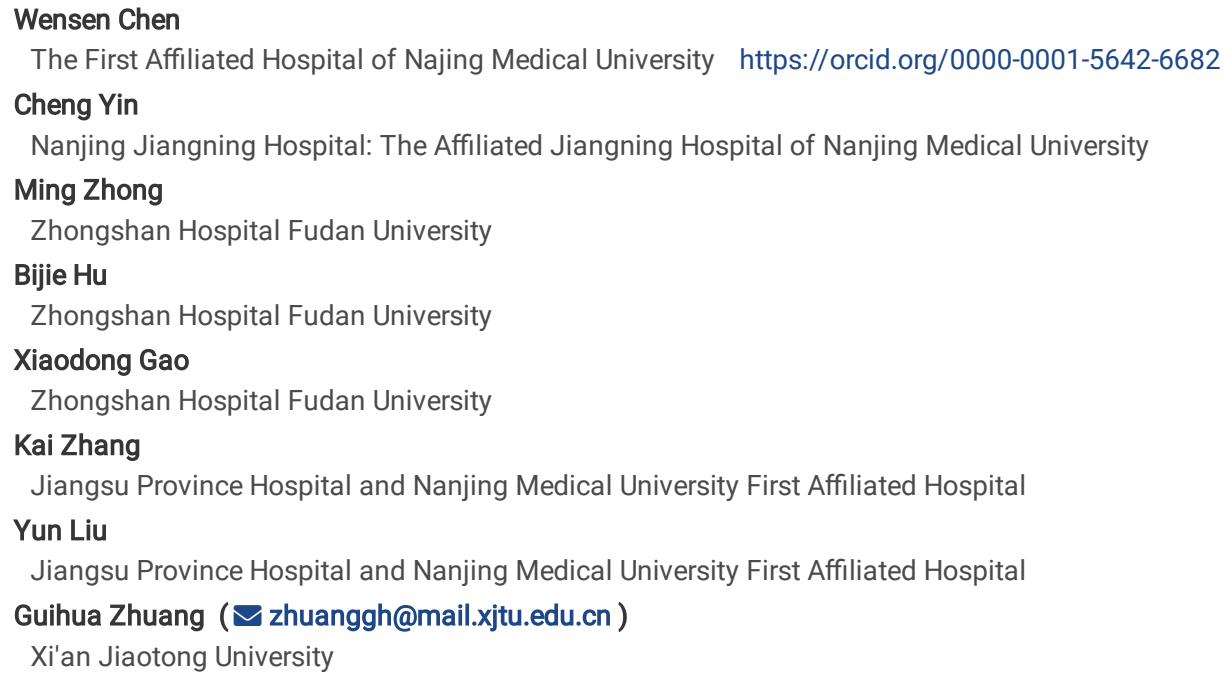




\section{Abstract}

\section{Background}

Patients with Coronavirus disease 2019 (COVID-19) admitted to an intensive care unit (ICU) might develop COVID-19-related pulmonary Aspergillosis (CAPA). We aimed to identify studies systematically that describe the incidence and risks factors of CAPA, and to assess its outcome.

\section{Methods}

Two authors independently searched ScienceDirect, PubMed, CNKI, MEDLINE (OVID), and MedRXIV from December 31, 2019 to Feb 27, 2021. We included observational cohort studies that investigated patients with CAPA admitted to an ICU. We assessed the quality of all included studies using the NewcastleOttawa Scale). The meta-analysis was registered with PROSPERO (CRD42021242179).

\section{Results}

Twenty-nine cohort studies with 2095 patients with COVID-19 admitted to an ICU and 264 patients who developed to CAPA were included (Pooled incidence: $0.14,95 \%$ confidence interval $[\mathrm{Cl}]=0.11-0.17)$. The overall mortality and case fatality rate of CAPA were $0.07(0.05-0.09)$ and $0.51(0.44-0.58)$, respectively. Patients with COVID-19 would develop CAPA at 7.28 days after mechanical ventilation (range, 5.48-9.08). Compared with patients without CAPA, those with CAPA had a significantly lower median body mass index (27.32 vs. $\left.28.97 \mathrm{~kg} / \mathrm{m}^{2}, P=0.034\right)$, higher median creatinine level (127.94 vs. $\left.88.23 \mu \mathrm{mol} / \mathrm{L}, P=014\right)$, and were more likely to receive corticosteroids therapy $(41.0 \%$ vs. $38.0 \%$, risk ratio $[\mathrm{RR}]=1.98,95 \% \mathrm{Cl}=1.08-3.63)$ and renal replacement therapy $(42.0 \%$ vs. $28.2 \%, \mathrm{RR}=1.61,95 \% \mathrm{Cl}=1.04-2.50)$ during admission. Remarkably, patients with CAPA were associated significantly with a 1.66-fold higher mortality (RR = $1.66,95 \% \mathrm{Cl}=1.31-2.12$ ) without significant heterogeneity and publication bias.

\section{Conclusions}

Patients with COVID-19 admitted to an ICU might develop CAPA and have higher all-cause mortality. We recommend conducting prospective screening for CAPA among patients with severe COVID-19, especially for those who receive mechanical ventilation over 7 days.

\section{Introduction}

From December 2019, a pandemic of coronavirus disease 2019 (COVID-19) caused by the novel severe acute respiratory syndrome coronavirus 2 (SARS-CoV2) spread rapidly from Asia to the rest of the world [1]. About 5\% of patients with COVID-19 require intensive care unit (ICU) management [2]. Clinicians are alert to the possibility of bacterial or fungal infection and prescribe antibiotics to nearly $90 \%$ of antibiotic patients with COVID-19 in the ICU setting [3]. Respiratory viruses (including SARSCoV-2) cause direct damage the airway epithelium [4], facilitating bacterial and fungi invasion. Furthermore, ciliary clearance is hampered by viral infection, resulting in immune dysfunction or dysregulation [5]. With severe pulmonary inflammation, longterm exposure to broad-spectrum antibiotics [6], and receipt of immunosuppressive drugs [7], patients with severe COVID-19 are at risk for secondary infections [8]. It was reported that $14 \%$ hospitalized patients with COVID-19 had bacterial co-infections in mixed ward or ICU settings [9]. Increasing numbers of studies have drawn attention to the high prevalence of COVID-19 associated pulmonary Aspergillosis (CAPA) in patients with severe COVID-19 [2, 10-12] admitted to the ICU. A diagnosis of CAPA was made based on specific case definitions or diagnostic algorithms, including the AspICU algorithm, Modified AspICU algorithm, influenza-associated pulmonary aspergillosis (IAPA) criteria, the European Organization for Research and Treatment of Cancer/Invasive Fungal Infections Cooperative Group, the National Institute of Allergy and Infectious Diseases Mycoses Study Group (EORTC/MSG), the European Confederation for Medical Mycology, and the International Society for Human and Animal Mycology (ECMM/ISHAM) consensus criteria. However, the exact incidence of CAPA remains unknown and opinions are polarized [13-16]. Currently, reports on the incidence, risk factors, and outcomes of CAPA remain inconclusive. To address this gap in the literature, we conducted this systematic review and meta-analysis of 29 cohort studies, with the aim of identifying studies that describe the incidence and risks factors of CAPA, and then assessing the outcome of CAPA.

\section{Methods}

This systematic review was based on a prospectively registered protocol (PROSPERO CRD42021242179) and was conducted in accordance to the Preferred Reporting Items for Systematic Reviews and Meta-Analyses (PRISMA) guidelines [17]. The review process is illustrated in a flow diagram (Figure 1).

\section{Search Strategy}

A search string was developed to identify original research studies reporting clinical characteristics and outcomes of patients with CAPA. The search was applied to the following databases: ScienceDirect, PubMed, CNKI, MEDLINE (OVID), and MedRXIV. Searches were performed for each database from December 31, 2019 to Feb 27, 2021. The following key words were used in all database searches: "coronavirus", "COVID”, "COVID-19”, "severe acute respiratory syndrome", "coronavirus 2", "SARS-CoV-2", "Aspergillus", "pulmonary Aspergillus", "invasive Aspergillus", "invasive pulmonary Aspergillus", "COVID-19Associated pulmonary Aspergillosis" and "intensive care unit".

\section{Study Selection and Eligibility Criteria}

All references were collected and screened independently by two reviewers (Chen WS and Kai Zhang) against a set of predefined eligibility criteria. Potentially eligible studies were selected for full-text analysis. Disagreements were resolved by consensus or by appeal to a third senior reviewer (Liu Y). All observational cohort studies reporting the incidence and outcome of CAPA among patients with COVID-19 admitted to an ICU were included in this meta-analysis. The exclusion criteria included case control studies, case reports, nonhuman research, and meeting abstracts without a full article.

Page 2/12 


\section{Quality Assessment}

The quality of the included studies was assessed using the Newcastle-Ottawa Scale (NOS) by the two researchers who were involved in the literature search (Chen WS and Zhang K), who assessed the quality of all included studies and discussed discrepancies until a consensus was reached with the corresponding author (Zhuang GH).

\section{Data Extraction and Outcome Measures}

Data were extracted for the following variables: study period, sample size, definition of CAPA, age, sex, underlying disease, laboratory examination, exposure information of CAPA, and outcome. Mortality was defined as the number of deaths diagnosed with CAPA divided by the number of COVID-19 cases in the cohort. The case fatality rate (CFR) was defined as the number of CAPA deaths divided by the total number of CAPA cases in the cohort. The primary outcome was all-cause mortality and all-cause CFR during admission. The secondary outcome was the length of ICU stay for the patients with COVID-19.

\section{Statistical Analysis}

Random-effects meta-analysis [18] was used to reported the incidence, all-cause mortality, all-cause CFR, and risk ratios (RRs) with 95\% confidence intervals (Cls). For pooling of the means of numerical variables, we computed missing means and standard deviations (SDs) from medians; ranges (minimum to maximum); and inter-quartile ranges (IQRs); using the methods proposed by Hozo et al. [19]. Pooled proportions were computed using the inverse variance method and the variance-stabilizing Freeman-Tukey double arcsine transformation [20]. Subgroup analysis was conducted based on the literature design (prospective or retrospective study), the type of research centre (Single or Multi-centre), and the clinical characteristics of the patients (e.g., acute respiratory distress syndrome (ARDS), acute respiratory failure (ARF)). The Mantel-Haenszel estimator was used to calculate the between-study heterogeneity statistic $\mathrm{Q}$, which was used in the DerSimonian-Laird estimator. The $\mathrm{I}^{2}$ statistic was used to present between-study heterogeneity, where $\mathrm{I}^{2} 350 \%$ was considered substantial. We assessed publication bias using Egger's test and by inspecting funnel plots. Statistical analyses were performed using the R software version 3.6.3 (R Foundation for Statistical Computing, 2016), with the package "meta" and Stata Special Edition 15.1 (Stata Corp, College Station, TX, USA). P-values less than 0.05 were considered statistically significant.

\section{Results}

Our search algorithm in the MEDLINE, OVID, PubMed and MedRXIV databases retrieved 1441 records. We screened based on the title and abstract and excluded 1377 studies. Sixty-four articles were assessed for eligibility. Finally, we identified 29 observational cohort studies that qualified according to our predefined inclusion and exclusion criteria (Figure 1), which included a total of 2095 patients with COVID-19 admitted to an ICU.

\section{Characteristics of included studies}

Of the 29 studies, 8 (27.59\%) were from France [2, 13, 21-26], 4 (13.79\%) were from the United Kingdom (UK) [27-32], 4 (13.79\%) were from the Netherlands [33, 34], 2 (6.90\%) were from Germany [35, 36], 2 (6.90\%) were from Spain [15, 37], 2 (6.90\%) were from Switzerland [14, 38], 1 (3.45\%) was from the USA [39], 1 (3.45\%) was from Belgium [40], 1 (3.45\%) was from China[6], 1(3.45\%) was from Pakistan [41], 1(3.45\%) was from Denmark [42], 1 (3.45\%) was from Italy [43] and 1(3.45\%) from Mexico [44]. Twelve studies dealt with patients who received mechanical ventilation, eight studies were of patients with ARDS, one study was on extracorporeal membrane oxygenation (ECMO), 1 study looked at acute respiratory failure (ARF), and seven studies included other patients with severe COVID-19 (See additional file 1, supplementary 1 ).

\section{Quality control of included studies}

The risk of bias included in the cohort studies was assessed using the Newcastle-Ottawa-Scale (NOS) as presented in Table 1. The overall score was 141 out of $232(60.78 \%)$, which is considered to be indicative of moderate quality. All the eligible studies included patients with severe COVID-19 admitted to ICU. Among the studies, $34.48 \%$ (10/29) did not describe the determination of exposure. In addition, $72.41 \%(21 / 29)$ studies did not control the comparability of the cohorts on the basis of the design or analysis. Although all studies (29/29) followed up the patients for long enough for defined outcomes to occur, only $51.72 \%(15 / 29)$ demonstrated clearly the adequacy of follow up of the cohorts. All studies assessed the outcomes of interest based on medical record linkage (See additional file 1, supplementary 2).

\section{Incidence of CAPA}

In the studies, 2095 patients with severe COVID-19 admitted to an ICU were investigated and 264 cases of CAPA were reported. The incidence of CAPA was calculated as 0.14 (95\% confidence interval $\left.[\mathrm{Cl}]=0.11-0.17, \mathrm{I}^{2}=81.2 \%\right)$. In the sub-group analysis by study design, the incidence of CAPA was calculated at $0.14\left(95 \% \mathrm{Cl}=0.09-0.19, \mathrm{I}^{2}=87.4 \%\right)$ in the prospective studies and $0.14\left(95 \% \mathrm{Cl}=0.10-0.18, \mathrm{I}^{2}=74.1 \%\right)$ in the retrospective studies (Table 1$)$. When stratified analysis was undertaken by research centre (multi-centre or single centre), the CAPA incidence was $0.12\left(95 \% \mathrm{Cl}=0.10-0.15, \mathrm{I}^{2}=77.3 \%\right)$ for the single centre studies and $0.20\left(95 \% \mathrm{Cl}=0.12-0.28, \mathrm{I}^{2}=81.2 \%\right)$ for the multi-centre studies. We found a high heterogeneity for calculation of the incidence of CAPA and significant publication bias according to Egger's regression test (See additional file 1, supplementary 3 Figure A). Remarkably, we found that patients with COVID-19 admitted to an ICU would develop CAPA after approximately 7.28 days of mechanical ventilation (nine studies, $95 \%$ CI = 5.48--9.08, $I^{2}=46 \%$ ) (Figure 2).

\section{Colonisation by Aspergillus}


In five cohort studies including 365 patients with COVID-19 admitted to an ICU, 21 patients were assessed for Aspergillus colonisation. The calculated colonization rate of was $5.75 \%(21 / 365)$ (See additional file 1, supplementary 1 ), suggesting that clinicians should comprehensively analyse Aspergillus colonisation combined with other clinical evidence (such as imaging and inflammatory factors, etc.) to judge whether the patient might develop CAPA and require further anti-fungal treatment.

\section{All-cause mortality of CAPA}

Twenty-three studies were included in the final analysis, with 119 deceased patients and 2786 surviving patients. The overall mortality of CAPA was 0.07 ( $95 \%$ $\mathrm{Cl}=0.05-0.09, \mathrm{I}^{2}=64.2 \%$ ) among patients with severe COVID-19. In the subgroup analysis for study design, the calculated all-cause mortality of CAPA was $0.07\left(95 \% \mathrm{Cl}=0.04-0.10, \mathrm{I}^{2}=67.1 \%\right)$ for the prospective studies, $0.08\left(95 \% \mathrm{Cl}=0.05-0.11, \mathrm{I}^{2}=62.9\right)$ for the retrospective studies, $0.06(95 \% \mathrm{Cl}=0.09-0.09$, $\left.\mathrm{I}^{2}=0 \%\right)$ for the single centre studies, and $0.11\left(95 \% \mathrm{Cl}=0.06-0.16, \mathrm{I}^{2}=0 \%\right)$ for the multi-centre studies. There was significant publication bias on Egger's regression test (Table 1).

\section{CFR of CAPA}

Twenty-three studies were eligible for further analysis of all-cause CFR with 119 deceased patients and 145 surviving patients. We found that the pooled CFR was $0.51\left(95 \% \mathrm{Cl}, 0.44-0.58, \mathrm{I}^{2}=86.5 \%\right)$. In the subgroup analysis by study design, the calculated CFRs were $0.49\left(95 \% \mathrm{Cl}, 0.39-0.59, \mathrm{I}^{2}=88.4\right)$ for the prospective studies, $0.53\left(95 \% \mathrm{Cl}=0.43-0.63, \mathrm{I}^{2}=85.9 \%\right)$ for the retrospective studies, $0.50\left(95 \% \mathrm{Cl}=0.42-0.58, \mathrm{I}^{2}=86.5 \%\right)$ for the single centre studies, and $0.58\left(95 \% \mathrm{Cl}=0.42-0.73, \mathrm{I}^{2}=89.5 \%\right)$ for the multi-centre studies (Table 1$)$.

\section{Comparing patients with CAPA with those without CAPA (control)}

\section{Risk factors for CAPA}

Eleven studies were pooled to investigate and compared patients with and without CAPA (127 vs. 788 patients) (Table 2). No significant differences were observed regarding general population characteristics (age, sex, hypertension, diabetes, obesity, cardiovascular disease, history of cancer, chronic pulmonary disease, chronic kidney disease, an immunosuppression), blood examination (white blood cell [WBC] count, neutrophil count, lymphocyte count, creatinine, Creactive protein [CRP], and lactate dehydrogenase (LDH)), and respiratory sample characteristics at baseline (Table 2). Compared to patients without CAPA (control), patients with CAPA had a significantly lower median BMI (four studies, $27.32 \mathrm{vs.} 28.97 \mathrm{~kg} / \mathrm{m}^{2}, P=0.034$ ) and higher median creatinine (four studies, 127.94 vs. 88.23, $P=014$ ). No differences in the use of Lopinavir/ritonavir, Hydroxychloroquine (HCQ), Azithromycin, Tocilizumab, ventilated prone, and ECMO were observed in the patients with CAPA compared with those without (Table 2). However, compared with the controls, patients with CAPA were more likely to have received corticosteroids during admission (eight studies, $41.0 \%[41 / 100]$ vs. $38.0 \%[273 / 719]$, risk ratio $[\mathrm{RR}]=1.98,95 \% \mathrm{Cl}=1.08-3.63, \mathrm{I}^{2}=74.10 \%$ ) and renal replacement therapy (two studies, $42.0 \%$ [29/69] vs. 28.2\% [90/319], RR $\left.=1.61,95 \% \mathrm{Cl}=1.04-2.50, \mathrm{I}^{2}=32.5\right)(\mathrm{Table} 2)$.

\section{Outcome with CAPA or without CAPA}

Eleven studies were included. The analysis showed that patients with CAPA were associated significantly with a 1.66-fold higher risk for mortality (risk ratio $[R R]=1.66,95 \% \mathrm{Cl}=1.31-2.12, \mathrm{I}^{2}=22.5 \%$ ) (Figure 3 ) without significant heterogeneity and publication bias (See supplementary 3 ). In the subgroup analysis by study design, patients with CAPA were associated significantly with a 1.53-fold elevated risk of mortality ( $\operatorname{six}$ studies, RR $=1.53,95 \% \mathrm{Cl}=1.02-2.21, \mathrm{I}^{2}=$ 47.9) for the retrospective cohort studies, a 1.93 -fold elevated risk of mortality (five studies, $\mathrm{RR}=1.93,95 \% \mathrm{Cl}=1.37-2.71, \mathrm{I}^{2}=0 \%$ ) for the prospective cohort studies (Figure $3 \mathrm{~A}$ ), a 1.52-fold elevated risk of mortality (nine studies, RR $=1.52,95 \% \mathrm{Cl}=1.12-2.07, \mathrm{I}^{2}=24.7 \%$ ) the for single centre studies, and a $2.03-$ fold elevated risk of mortality (two studies, $\mathrm{RR}=2.03,95 \% \mathrm{Cl}=1.46-2.81, \mathrm{I}^{2}=0 \%$ ) for the multi-centre studies (Figure 3 B). No statistically significant difference was found in the length of ICU stay for CAPA and non-CAPA patients (MD $=5.58,95 \% \mathrm{Cl}=-1.93$ to $13.08, P=0.145)($ Table 2$)$.

\section{Discussion}

We conducted this systematic review of 29 cohort studies and observed that $14 \%$ of patients with COVID-19 admitted to the ICU developed CAPA. Meanwhile, the median time to develop CAPA among patients with COVID-19 who received mechanical ventilation was 7.28 days. Studies reported that the incidence of CAPA varied from $1.9-27.7 \%[14,43,45]$. This wide divergence might result an underestimate of the risk of CAPA. Invasive pulmonary Aspergillosis is a secondary infection of severe respiratory viral infection $[46,47]$ and these infections have been related with significant morbidity and mortality, even when appropriately diagnosed and treated [48]. CAPA not only occurred in immunosuppressed patients (e.g., those with acute myeloid leukaemia) [49], but also in immunocompetent patients with COVID-19 [48, 50]. COVID-19 was independently associated with CAPA [36]. However, we observed significant heterogeneity in the pooled analysis of CAPA incidence. Many hospitals do not commonly perform bronchoscopy for CAPA diagnosis or use PCR tests for Aspergillus species[51]. Non-standardized definitions of CAPA (See additional file 1, supplementary 4), differences in detection methods [52], and variations among research designs might have contributed to heterogeneity across the studies, which requires further investigation. Nevertheless, we still recommend that clinicians should be alert to the occurrence of CAPA in patients with COVID-19, especially in those receiving mechanical ventilation more than 7 days.

The patients with COVID-19 who had higher APACHE II scores [36] and complicated underlying diseases (such as hypertension, diabetes, and tumours) [53], were independently associated with CAPA. We found that patients with CAPA had a lower BMI and higher concentration of creatinine compared with those without. One study indicated that elevated serum creatinine level was an independent risk factor for neutropenia-related invasive Aspergillosis [54]. The roles of BMI and creatinine in CAPA deserve further investigation. In this study, no differences in use of Lopinavir/ritonavir, HCQ, Tocilizumab, ventilated prone, and ECMO were observed in the patients with CAPA (As shown in Table 2). However, patients with CAPA were more likely to have received corticosteroid therapy and renal replacement therapy during admission compared with the non-CAPA controls. Previous studies reported that the use of corticosteroids increased the 
risk of invasive pulmonary Aspergillosis significantly after severe viral infection (Influenza) [55]. Patients requiring dialysis and kidney transplantation were also at risk of invasive Aspergillosis [56]. Existing evidence supported the view that the use of corticosteroids and renal replacement therapy might play an important role in the progression of patients with COVID-19 with CAPA.

We pooled 11 cohort studies and observed that the patients with CAPA were associated significantly with a 1.66 -fold higher risk of mortality (1.66, $95 \% \mathrm{Cl}=$ $1.31-2.12, I^{2}=22.5 \%$ ) (Fig. 3) without significant heterogeneity and publication bias (See additional file 1, Supplementary 3 Figure D). The findings supported the view that patients with CAPA had uniformly worse outcomes compared to those without, regardless of the definitions used. Meanwhile, we investigated the outcome of CAPA and found that the overall mortality of CAPA in COVID-19 patients in the ICU was 0.07 (Pooled mortality $=0.07,95 \% \mathrm{Cl}=0.05-0.10)$. The occurrence of CAPA would exacerbate the deterioration of respiratory function, thus increasing the risk of death. We pooled the studies and found that the allcause CFR of patients with CAPA was $51 \%$. Among all included studies, a very high proportion of patients with COVID-19 received mechanical ventilation. The proportion of patients receiving baseline mechanical ventilation in the 13 studies was more than $89 \%$ (11 studies, $100 \%$ mechanical ventilation). A systematic review has revealed that the CFR of patients with COVID-19 receiving mechanical ventilation was $45 \%$ (95\% $\mathrm{Cl}, 39-52 \%)$ [57]. Meijer and others conducted a small-sample cohort study (66 ICU patients with COVID-19) and found that the incidence of CAPA was $19.7 \%(n=13 / 66)$, and the fatality rate of a single study was $46.2 \%(6 / 13)$; the author's team listed some of the articles that have been published and analysed for the CAPA fatality rate. The pooled CFR for CAPA was $47 \%(62 / 132)$ [32].

The NOS was used to evaluate the quality of the included articles. We found that the selected studies were of medium quality (60.78\%). The most often overlooked factors were the representativeness of the exposed cohort, determination of exposure, comparability of the cohorts on the design or analysis, and the adequacy of the follow up of the cohorts (these four factors were scored as $0 \%, 34.48 \%, 27.59 \%$, and $51.72 \%$, respectively), which should be improved in future cohort studies. Meanwhile, we pooled the studies to investigate the incidence of CAPA incidence and CFR, and observed significant research heterogeneity. On the one hand, because of the lack of comparison of individual rates, heterogeneity occurred easily [57]. On the other hand, there was lack of a unified definition of CAPA (See supplementary 4) and a standard diagnostic algorithm in the published studies. Although we strictly controlled quality based on the study entry and exclusion criteria, heterogeneity between studies was still unavoidable. This meta-analysis did not explore the risk factors for mortality in patients with CAPA because of insufficient literature support. Further well designed research and demonstration would be warranted in the future.

\section{Conclusion}

In this study, the pooled incidence of CAPA was estimated as $14 \%$ among patients with COVID-19 admitted to the ICU, with high rate of all cause-mortality and CFR. We recommend that clinicians establish standardized screening methods for CAPA and to identify high risk patients early, especially for patients who have been mechanically ventilated for more than 7 days. Host factors (BMI and creatinine level) and the treatment of COVID-19 (the use of corticosteroids and renal replacement therapy) would significantly affect the development of CAPA.

\section{Abbreviations}

COVID-19: Coronavirus disease 2019

CAPA: COVID-19-Associated pulmonary Aspergillosis

ICU: Intensive care unit

CFR: case fatality rate

RR: Risk ratio

MD: Mean difference

Cl: Confidence intervals

\section{Declarations}

\section{Availability of data and materials}

The datasets synthesized during the current study are available from the corresponding author on reasonable request.

\section{Acknowledgements}

We are grateful to all health-care workers of Critical Care Medical Team of Jiangsu Province for their fight against the COVID-19 in Wuhan (Yun Liu, the team leader) and their assistance for this this meta-analysis.

\section{Funding}

This work was supported by grants from the National Key Research \& Development plan of Ministry of Science and Technology of the People's Republic of China (grant numbers 2018YFC1314900, 2018YFC1314901, 2020YFC0848100).

\section{Author information}


Wensen Chen and Cheng Yin contributed equally to this article.

Affiliations

Department of Epidemiology and Biostatistics, School of Public Health, Xi'an Jiao tong University Health Science Center, Xi'an, Shaanxi 710061, China.

Wensen Chen and Guihua Zhuang

Department of Infection Management, The First Affiliated Hospital of Nanjing Medical University, Nanjing, Jiangsu 210029, China.

Wensen Chen

Department of Laboratory Medicine, The Affiliated Hospital of Jiangning Hospital of Nanjing Medical University, Nanjing, Jiangsu 211100, China

Cheng Yin

Department of Critical Care Medicine, Zhongshan Hospital Fudan University, Shanghai 200032, China.

Ming Zhong

Department of Infectious Diseases\& Department of Infection Management, Zhongshan Hospital Fudan University, Shanghai 200032, China.

Bijie Hu and Xiaodong Gao

Pancreas Center, The First Affiliated Hospital of Nanjing Medical University, Nanjing, Jiangsu 210029, China.

Kai Zhang

School of Biomedical Engineering and Informatics, Nanjing Medical University, Nanjing 210096, China.

Yun Liu

Contributions

CWS and ZK searched the literature, collected the data, assessed the quality of references, and performed statistical analyses. CWS and CY drafted the manuscript. ZM, HBJ and GXD directed, reviewed, and revised the manuscript. LY and ZGH conducted the study design, supervised the collection of data and statistical analyses. All authors read and approved the final manuscript.

\section{Corresponding author}

Guihua Zhuang (zhuanggh@mail.xjtu.edu.cn) and Yun Liu (liuyun@njmu.edu.cn) are considered as joint corresponding authors.

\section{Ethics approval and consent to participate}

Not applicable.

\section{Consent for publication}

Not applicable.

\section{Competing interests}

All other authors have no conflicts of interest to declare.

\section{References}

1. Huang C, Wang Y, Li X, Ren L, Zhao J, Hu Y, Zhang L, Fan G, Xu J, Gu X, et al. Clinical features of patients infected with 2019 novel coronavirus in Wuhan, China. Lancet. 2020;395(10223):497-506.

2. Alanio A, Delliere S, Fodil S, Bretagne S, Megarbane B. Prevalence of putative invasive pulmonary aspergillosis in critically ill patients with COVID-19. Lancet Respir Med. 2020;8(6):e48-9.

3. Zhou F, Yu T, Du R, Fan G, Liu Y, Liu Z, Xiang J, Wang Y, Song B, Gu X, et al. Clinical course and risk factors for mortality of adult inpatients with COVID-19 in Wuhan, China: a retrospective cohort study. Lancet. 2020;395(10229):1054-62.

4. Short KR, Kasper J, van der Aa S, Andeweg AC, Zaaraoui-Boutahar F, Goeijenbier M, Richard M, Herold S, Becker C, Scott DP, et al. Influenza virus damages the alveolar barrier by disrupting epithelial cell tight junctions. Eur Respir J. 2016;47(3):954-66.

5. Herold S, Becker C, Ridge KM, Budinger GR. Influenza virus-induced lung injury: pathogenesis and implications for treatment. Eur Respir J. 2015;45(5):1463-78.

6. Wang J, Yang Q, Zhang P, Sheng J, Zhou J, Qu T. Clinical characteristics of invasive pulmonary aspergillosis in patients with COVID-19 in Zhejiang, China: a retrospective case series. Crit Care (London England). 2020;24(1):299. 
7. Kim MS, An MH, Kim WJ, Hwang TH. Comparative efficacy and safety of pharmacological interventions for the treatment of COVID-19: A systematic review and network meta-analysis. PLoS Med. 2020;17(12):e1003501.

8. Lescure FX, Bouadma L, Nguyen D, Parisey M, Wicky PH, Behillil S, Gaymard A, Bouscambert-Duchamp M, Donati F, Le Hingrat Q, et al. Clinical and virological data of the first cases of COVID-19 in Europe: a case series. The Lancet Infectious diseases. 2020;20(6):697-706.

9. Lansbury L, Lim B, Baskaran V, Lim WS. Co-infections in people with COVID-19: a systematic review and meta-analysis. J Infect. 2020;81(2):266-75.

10. Bartoletti M, Pascale R, Cricca M, Rinaldi M, Maccaro A, Bussini L, Fornaro G, Tonetti T, Pizzilli G, Francalanci E, et al: Epidemiology of invasive pulmonary aspergillosis among COVID-19 intubated patients: a prospective study. Clinical infectious diseases: an official publication of the Infectious Diseases Society of America 2020.

11. Machado M, Valerio M, Álvarez-Uría A, Olmedo M, Veintimilla C, Padilla B, De la Villa S, Guinea J, Escribano P, Ruiz-Serrano MJ, et al. Invasive pulmonary aspergillosis in the COVID-19 era: An expected new entity. Mycoses. 2021;64(2):132-43.

12. Marr KA, Platt A, Tornheim JA, Zhang SX, Datta K, Cardozo C, Garcia-Vidal C. Aspergillosis Complicating Severe Coronavirus Disease. Emerging infectious diseases 2021, 27(1).

13. Gouzien L, Cocherie T, Eloy O, Legriel S, Bedos JP, Simon C, Marque-Juillet S, Ferre A, Bruneel F. Invasive Aspergillosis Associated with severe COVID-19: A Word of Caution. Infectious diseases now, 2021.

14. Lamoth F, Glampedakis E, Boillat-Blanco N, Oddo M, Pagani JL. Incidence of invasive pulmonary aspergillosis among critically ill COVID-19 patients. Clinical microbiology infection: the official publication of the European Society of Clinical Microbiology Infectious Diseases. 2020;26(12):1706-8.

15. Segrelles-Calvo G, Araújo GRS, Llopis-Pastor E, Carrillo J, Hernández-Hernández M, Rey L, Rodríguez Melean N, Escribano I, Antón E, Zamarro C, et al. Prevalence of opportunistic invasive aspergillosis in COVID-19 patients with severe pneumonia. Mycoses. 2021;64(2):144-51.

16. Apostolopoulou A, Esquer Garrigos Z, Vijayvargiya P, Lerner AH, Farmakiotis D. Invasive Pulmonary Aspergillosis in Patients with SARS-CoV-2 Infection: A Systematic Review of the Literature. Diagnostics 2020, 10(10).

17. Moher D, Liberati A, Tetzlaff J, Altman DG, Group P. Preferred reporting items for systematic reviews and meta-analyses: the PRISMA statement. PLoS Med. 2009;6(7):e1000097.

18. Borenstein M, Hedges LV, Higgins JP, Rothstein HR. A basic introduction to fixed-effect and random-effects models for meta-analysis. Res Synth Methods. 2010;1(2):97-111.

19. Hozo SP, Djulbegovic B, Hozo I. Estimating the mean and variance from the median, range, and the size of a sample. BMC Med Res Methodol. $2005 ; 5: 13$.

20. Nyaga VN, Arbyn M, Aerts M. Metaprop: a Stata command to perform meta-analysis of binomial data. Arch Public Health. 2014;72(1):39.

21. Razazi K, Arrestier R, Haudebourg AF, Benelli B, Carteaux G, Decousser JW, Fourati S, Woerther PL, Schlemmer F, Charles-Nelson A, et al. Risks of ventilatorassociated pneumonia and invasive pulmonary aspergillosis in patients with viral acute respiratory distress syndrome related or not to Coronavirus 19 disease. Crit Care (London England). 2020;24(1):699.

22. Chauvet P, Mallat J, Arumadura C, Vangrunderbeek N, Dupre C, Pauquet P, Orfi A, Granier M, Lemyze M. Risk Factors for Invasive Pulmonary Aspergillosis in Critically III Patients With Coronavirus Disease 2019-Induced Acute Respiratory Distress Syndrome. Critical care explorations. 2020;2(11):e0244.

23. Fekkar A, Lampros A, Mayaux J, Poignon C, Demeret S, Constantin JM, Marcelin AG, Monsel A, Luyt CE, Blaize M. Occurrence of Invasive Pulmonary Fungal Infections in Patients with Severe COVID-19 Admitted to the ICU. Am J Respir Crit Care Med. 2021;203(3):307-17.

24. Dupont D, Menotti J, Turc J, Miossec C, Wallet F, Richard JC, Argaud L, Paulus S, Wallon M, Ader F, et al: Pulmonary aspergillosis in critically ill patients with Coronavirus Disease 2019 (COVID-19). Medical mycology 2021, 59(1):110-114.

25. Dellière S, Dudoignon E, Fodil S, Voicu S, Collet M, Oillic PA, Salmona M, Dépret F, Ghelfenstein-Ferreira T, Plaud B, et al: Risk factors associated with COVID-19-associated pulmonary aspergillosis in ICU patients: a French multicentric retrospective cohort. Clinical microbiology and infection: the official publication of the European Society of Clinical Microbiology and Infectious Diseases 2020.

26. Gangneux JP, Reizine F, Guegan H, Pinceaux K, Le Balch P, Prat E, Pelletier R, Belaz S, Le Souhaitier M, Le Tulzo Y, et al: Is the CoVID-19 Pandemic a Good Time to Include Aspergillus Molecular Detection to Categorize Aspergillosis in ICU Patients? A Monocentric Experience. Journal of fungi (Basel, Switzerland) 2020, 6(3).

27. Alcolea-Medina TCharalampous,Adela, Tom LBS, Williams GS, Rahul Batra1,3, Luigi Camporota, Christopher I.S. Meadows, Duncan Wyncoll, Nicholas A. Barrett, Carolyn J. Hemsley, Lisa Bryan, William Newsholme, Sara E. Boyd3, Anna Green, Ula Mahadeva, Amita Patel, Penelope R. Cliff, Andrew J. Page, Justin O'Grady and Jonathan D.Edgeworth: Application of respiratory metagenomics for COVID-19 patients on the intensive care unit to inform appropriate initial antimicrobial treatment and rapid detection of nosocomial transmission. medRxiv 2020.

28. Borman AM, Palmer MD, Fraser M, Patterson Z, Mann C, Oliver D, Linton CJ, Gough M, Brown P, Dzietczyk A, et al: CoVID-19-Associated Invasive Aspergillosis: Data from the UK National Mycology Reference Laboratory. Journal of clinical microbiology 2020, 59(1).

29. Maes M, Higginson E, Pereira-Dias J, Curran MD, Parmar S, Khokhar F, Cuchet-Lourenço D, Lux J, Sharma-Hajela S, Ravenhill B, et al. Ventilator-associated pneumonia in critically ill patients with COVID-19. Crit Care (London England). 2021;25(1):25.

30. White PL, Dhillon R, Cordey A, Hughes H, Faggian F, Soni S, Pandey M, Whitaker H, May A, Morgan M, et al: A national strategy to diagnose CoVID-19 associated invasive fungal disease in the ICU. Clinical infectious diseases: an official publication of the Infectious Diseases Society of America 2020.

31. van Grootveld R, van Paassen J, de Boer MGJ, Claas ECJ, Kuijper EJ, van der Beek MT. Group L-C-R: Systematic screening for CoVID-19 associated invasive aspergillosis in ICU patients by culture and PCR on tracheal aspirate. Mycoses 2021.

32. Meijer EFJ, Dofferhoff ASM, Hoiting O, Meis JF. COVID-19-associated pulmonary aspergillosis: a prospective single-center dual case series. Mycoses. 2021;64(4):457-64. 
33. Van Biesen S, Kwa D, Bosman RJ, Juffermans NP. Detection of Invasive Pulmonary Aspergillosis in CoVID-19 with Non-directed Bronchoalveolar Lavage. American journal of respiratory and critical care medicine 2020.

34. van Arkel ALE, Rijpstra TA, Belderbos HNA, van Wijngaarden P, Verweij PE, Bentvelsen RG. COVID-19-associated Pulmonary Aspergillosis. Am J Respir Crit Care Med. 2020;202(1):132-5.

35. Koehler P, Cornely OA, Böttiger BW, Dusse F, Eichenauer DA, Fuchs F, Hallek M, Jung N, Klein F, Persigehl T, et al. COVID-19 associated pulmonary aspergillosis. Mycoses. 2020;63(6):528-34.

36. Lahmer T, Kriescher S, Herner A, Rothe K, Spinner CD, Schneider J, Mayer U, Neuenhahn M, Hoffmann D, Geisler F, et al. Invasive pulmonary aspergillosis in critically ill patients with severe COVID-19 pneumonia: Results from the prospective AspCOVID-19 study. PloS one. 2021;16(3):e0238825.

37. Nebreda-Mayoral T, Miguel-Gomez MA, March-Rossello GA, Puente-Fuertes L, Canton-Benito E, Martinez-Garcia AM, Munoz-Martin AB, Orduna-Domingo A. Bacterial/fungal infection in hospitalized patients with COVID-19 in a tertiary hospital in the Community of Castilla y Leon, Spain. Enferm Infecc Microbiol Clin 2020.

38. Philipp K, Buehler1 ASZ, Daniel A. Hofmaenner PD, Wendel García, Claudio T, Acevedo, Alejandro Gómez-Mejia; Srikanth Mairpady Shambat, Federica Andreoni, Martina A. Maibach, Jan Bartussek, Matthias P. Hilty, Pascal M. Frey, Reto A. Schuepbach, Silvio D. Brugger: Bacterial pulmonary superinfections are associated with unfavourable outcomes in critically ill COVID-19 patients. medRxiv 2020.

39. Mitaka H, Perlman DC, Javaid W, Salomon N. Putative invasive pulmonary aspergillosis in critically ill patients with COVID-19: An observational study from New York City. Mycoses. 2020;63(12):1368-72.

40. Rutsaert L, Steinfort N, Van Hunsel T, Bomans P, Naesens R, Mertes H, Dits H, Van Regenmortel N. COVID-19-associated invasive pulmonary aspergillosis. Ann Intensiv Care. 2020;10(1):71.

41. Nasir N, Farooqi J, Mahmood SF, Jabeen K. COVID-19-associated pulmonary aspergillosis (CAPA) in patients admitted with severe COVID-19 pneumonia: An observational study from Pakistan. Mycoses. 2020;63(8):766-70.

42. Helleberg M, Steensen M, Arendrup MC. Invasive aspergillosis in patients with severe COVID-19 pneumonia. Clinical microbiology infection: the official publication of the European Society of Clinical Microbiology Infectious Diseases. 2021;27(1):147-8.

43. Bartoletti M, Pascale R, Cricca M, Rinaldi M, Maccaro A, Bussini L, Fornaro G, Tonetti T, Pizzilli G, Francalanci E, et al: Epidemiology of invasive pulmonary aspergillosis among COVID-19 intubated patients: a prospective study. Clinical infectious diseases: an official publication of the Infectious Diseases Society of America 2020.

44. Roman-Montes CM, Martinez-Gamboa A, Diaz-Lomeli P, Cervantes-Sanchez A, Rangel-Cordero A, Sifuentes-Osornio J, Ponce-de-Leon A, Gonzalez-Lara MF. Accuracy of galactomannan testing on tracheal aspirates in COVID-19-associated pulmonary aspergillosis. Mycoses. 2021;64(4):364-71.

45. Gouzien L, Cocherie T, Eloy O, Legriel S, Bedos JP, Simon C, Marque-Juillet S, Ferré A, Bruneel F. Invasive Aspergillosis Associated with severe CoVID-19: A Word of Caution. Infectious diseases now, 2021

46. Schwartz IS, Friedman DZP, Zapernick L, Dingle TC, Lee N, Sligl W, Zelyas N, Smith SW: High Rates of Influenza-Associated Invasive Pulmonary Aspergillosis May Not Be Universal: A Retrospective Cohort Study from Alberta, Canada. Clinical infectious diseases: an official publication of the Infectious Diseases Society of America 2020, 71(7):1760-1763.

47. Wauters J, Baar I, Meersseman P, Meersseman W, Dams K, De Paep R, Lagrou K, Wilmer A, Jorens P, Hermans G. Invasive pulmonary aspergillosis is a frequent complication of critically ill H1N1 patients: a retrospective study. Intensive care medicine. 2012;38(11):1761-8.

48. Hakamifard A, Hashemi M, Fakhim H, Aboutalebian S, Hajiahmadi S, Mohammadi R. Fatal disseminated aspergillosis in an immunocompetent patient with COVID-19 due to Aspergillus ochraceus. Journal de mycologie medicale. 2021;31(2):101124.

49. Nasri E, Shoaei P, Vakili B, Mirhendi H, Sadeghi S, Hajiahmadi S, Sadeghi A, Vaezi A, Badali H, Fakhim H. Fatal Invasive Pulmonary Aspergillosis in COVID19 Patient with Acute Myeloid Leukemia in Iran. Mycopathologia. 2020;185(6):1077-84.

50. Haglund A, Christensen S, Kristensen L, Gertsen JB, Buus L, Lausch KR. Invasive pulmonary aspergillosis and hyperthermia in an immunocompetent patient with COVID-19. Medical mycology case reports. 2021;31:29-31.

51. Wahidi MM, Shojaee S, Lamb CR, Ost D, Maldonado F, Eapen G, Caroff DA, Stevens MP, Ouellette DR, Lilly C, et al. The Use of Bronchoscopy During the Coronavirus Disease 2019 Pandemic: CHEST/AABIP Guideline and Expert Panel Report. Chest. 2020;158(3):1268-81.

52. Koehler P, Bassetti M, Chakrabarti A, Chen SCA, Colombo AL, Hoenigl M, Klimko N, Lass-Flörl C, Oladele RO, Vinh DC, et al: Defining and managing COVID19-associated pulmonary aspergillosis: the 2020 ECMM/ISHAM consensus criteria for research and clinical guidance. The Lancet Infectious diseases 2020.

53. Ng WH, Tipih T, Makoah NA, Vermeulen JG, Goedhals D, Sempa JB, Burt FJ, Taylor A, Mahalingam S. Comorbidities in SARS-CoV-2 Patients: a Systematic Review and Meta-Analysis. mBio 2021, 12(1).

54. Nouer SA, Nucci M, Kumar NS, Grazziutti M, Restrepo A, Anaissie E. Baseline platelet count and creatinine clearance rate predict the outcome of neutropenia-related invasive aspergillosis. Clinical infectious diseases: an official publication of the Infectious Diseases Society of America. 2012;54(12):e173-83.

55. Schauwvlieghe A, Rijnders BJA, Philips N, Verwijs R, Vanderbeke L, Van Tienen C, Lagrou K, Verweij PE, Van de Veerdonk FL, Gommers D, et al. Invasive aspergillosis in patients admitted to the intensive care unit with severe influenza: a retrospective cohort study. Lancet Respir Med. 2018;6(10):782-92.

56. Pegorie M, Denning DW, Welfare W. Estimating the burden of invasive and serious fungal disease in the United Kingdom. J Infect. 2017;74(1):60-71.

57. Lim ZJ, Subramaniam A, Ponnapa Reddy M, Blecher G, Kadam U, Afroz A, Billah B, Ashwin S, Kubicki M, Bilotta F, et al: Case Fatality Rates for Patients with COVID-19 Requiring Invasive Mechanical Ventilation. A Meta-analysis. American journal of respiratory and critical care medicine 2021, 203(1):54-66. 
Tables

Table 1 The incidence, mortality and CFR of CAPA among all 29 included studies

\begin{tabular}{|c|c|c|c|c|c|c|c|c|c|c|c|c|}
\hline \multirow[t]{2}{*}{ Variable } & \multicolumn{5}{|c|}{ Incidence of CAPA } & \multicolumn{5}{|c|}{ Mortality of CAPA } & \multicolumn{2}{|l|}{ CFR of CAPA } \\
\hline & References & $\begin{array}{l}\text { CAPA } \\
\text { patients/Total }\end{array}$ & Effect & $\begin{array}{l}95 \% \\
\mathrm{Cl}\end{array}$ & $\begin{array}{l}\mathrm{I}^{2} \\
(\%)\end{array}$ & References & $\begin{array}{l}\text { Deceased/ } \\
\text { Total }\end{array}$ & Effect & $\begin{array}{l}95 \% \\
\mathrm{Cl}\end{array}$ & $\begin{array}{l}\mathrm{I}^{2} \\
(\%)\end{array}$ & References & $\begin{array}{l}\text { Deceased/ } \\
\text { CAPA } \\
\text { patients }\end{array}$ \\
\hline Overall & 29 & $264 / 2095$ & 0.14 & $\begin{array}{l}0.11- \\
0.17\end{array}$ & 81.2 & 23 & 119/2095 & 0.07 & $\begin{array}{l}0.05- \\
0.10\end{array}$ & 64.2 & 23 & $119 / 264$ \\
\hline \multicolumn{13}{|l|}{ Study design } \\
\hline Prospective & 11 & $124 / 1041$ & 0.14 & $\begin{array}{l}0.09- \\
0.19\end{array}$ & 87.4 & 10 & $58 / 1041$ & 0.07 & $\begin{array}{l}0.04- \\
0.10\end{array}$ & 67.1 & 10 & $58 / 124$ \\
\hline Retrospective & 18 & $140 / 1054$ & 0.14 & $\begin{array}{l}0.10- \\
0.18\end{array}$ & 74.1 & 13 & $61 / 1054$ & 0.08 & $\begin{array}{l}0.05- \\
0.11\end{array}$ & 62.9 & 13 & $61 / 140$ \\
\hline \multicolumn{13}{|l|}{ Centers } \\
\hline Single-center & 26 & $194 / 1744$ & 0.12 & $\begin{array}{l}0.10^{-} \\
0.15\end{array}$ & 77.3 & 20 & 78/1744 & 0.06 & $\begin{array}{l}0.03- \\
0.09\end{array}$ & 0 & 20 & 78/194 \\
\hline Multi-center & 3 & $70 / 351$ & 0.20 & $\begin{array}{l}0.12- \\
0.28\end{array}$ & 81.2 & 3 & $41 / 351$ & 0.11 & $\begin{array}{l}0.06- \\
0.16\end{array}$ & 0 & 3 & $41 / 70$ \\
\hline \multicolumn{13}{|l|}{ Characteristics } \\
\hline MV & 12 & 98/932 & 0.11 & $\begin{array}{l}0.07- \\
0.15\end{array}$ & 77.5 & 9 & 46/932 & 0.06 & $\begin{array}{l}0.03- \\
0.09\end{array}$ & 64.1 & 9 & $46 / 98$ \\
\hline ARDS & 5 & $40 / 239$ & 0.16 & $\begin{array}{l}0.11- \\
0.20\end{array}$ & 0 & 5 & $20 / 239$ & 0.08 & $\begin{array}{l}0.04- \\
0.11\end{array}$ & 0 & 5 & $20 / 40$ \\
\hline ARDS, MV & 3 & $44 / 243$ & 0.17 & $\begin{array}{l}0.04- \\
0.30\end{array}$ & 86.8 & 2 & $15 / 243$ & 0.08 & $\begin{array}{l}0.01- \\
0.16\end{array}$ & 66.9 & 2 & $15 / 44$ \\
\hline ARF, MV & 1 & $11 / 32$ & 0.34 & $\begin{array}{l}0.18- \\
0.51\end{array}$ & 0 & 1 & $4 / 32$ & 0.13 & $\begin{array}{l}0.01- \\
0.24\end{array}$ & 0 & 1 & $4 / 11$ \\
\hline ECMO & 1 & $2 / 8$ & 0.25 & $\begin{array}{l}-0.05- \\
0.55\end{array}$ & 0 & 1 & $2 / 8$ & 0.25 & $\begin{array}{l}-0.05- \\
0.55\end{array}$ & 0 & 1 & $2 / 2$ \\
\hline Unknown & 7 & $69 / 641$ & 0.14 & $\begin{array}{l}0.07- \\
0.21\end{array}$ & 86.5 & 5 & $32 / 641$ & 0.08 & $\begin{array}{l}0.02- \\
0.13\end{array}$ & 82.1 & 5 & $32 / 69$ \\
\hline
\end{tabular}

Abbreviation: CFR, case fatality rate; MV, mechanical ventilation; ARDS, acute respiratory distress syndrome;

Table2 Pooled analysis of risk factors compared CAPA with Non-CAPA patients among 11 cohort studies 


\begin{tabular}{|c|c|c|c|c|c|c|c|c|}
\hline \multirow[t]{2}{*}{ Variable } & \multirow{2}{*}{$\begin{array}{l}\text { References } \\
(\mathrm{N})^{\mathrm{a}}\end{array}$} & \multirow{2}{*}{$\begin{array}{l}\text { CAPA } \\
\text { Event/Total or } \\
\text { mean } \pm S D\end{array}$} & \multirow{2}{*}{$\begin{array}{l}\text { Non-CAPA } \\
\text { (Control) } \\
\text { Event/Total or } \\
\text { mean } \pm S D\end{array}$} & \multicolumn{3}{|c|}{ Random effects model } & \multirow[t]{2}{*}{$\mathrm{I}^{2}(\%)$} & \multirow{2}{*}{$\begin{array}{l}\text { P value for } \\
\text { heterogeneity }\end{array}$} \\
\hline & & & & $\begin{array}{l}\text { Effects } \\
\text { (RR or } \\
\text { MD) }\end{array}$ & $95 \% \mathrm{Cl}$ & $\begin{array}{l}\mathrm{P}- \\
\text { value }\end{array}$ & & \\
\hline Age (years), Mean $\pm S D$ & 8 & $63.84 \pm 1.18$ & $60.40 \pm 1.58$ & 1.65 & $\begin{array}{l}{[-0.99-} \\
4.30]\end{array}$ & 0.220 & 0.00 & 0.686 \\
\hline Men, $\mathrm{N}$ & 9 & $85 / 111$ & $436 / 562$ & 0.77 & $\begin{array}{l}{[0.46-} \\
1.29]\end{array}$ & 0.326 & 0.00 & 0.594 \\
\hline BMI $(\mathrm{Kg} / \mathrm{m} 2)$, Mean $\pm S D$ & 4 & $27.32 \pm 0.83$ & $28.97 \pm 0.47$ & -1.19 & $\begin{array}{l}{[-2.28-} \\
-0.09]\end{array}$ & 0.034 & 3.60 & 0.375 \\
\hline \multicolumn{9}{|l|}{ Underlying disease } \\
\hline Hypertension, n/N & 6 & $43 / 78$ & $187 / 395$ & 1.41 & $\begin{array}{l}{[0.63-} \\
3.13]\end{array}$ & 0.399 & 44.40 & 0.109 \\
\hline Diabetes, $\mathrm{n} / \mathrm{N}$ & 8 & $28 / 105$ & $162 / 537$ & 0.96 & $\begin{array}{l}{[0.58-} \\
1.57]\end{array}$ & 0.863 & 0.00 & 0.965 \\
\hline Obesity, n/N & 5 & $32 / 78$ & $256 / 453$ & 0.72 & $\begin{array}{l}{[0.42-} \\
1.25]\end{array}$ & 0.247 & 0.00 & 0.473 \\
\hline CVD, $n / N$ & 3 & $5 / 39$ & $17 / 138$ & 1.28 & $\begin{array}{l}{[0.41-} \\
4.04]\end{array}$ & 0.672 & 1.00 & 0.364 \\
\hline $\begin{array}{l}\text { Chronic pulmonary disease (e.g. , } \\
\text { COPD, Asthma), n/N }\end{array}$ & 6 & $15 / 84$ & $35 / 392$ & 2.49 & $\begin{array}{l}{[0.92-} \\
6.62]\end{array}$ & 0.072 & 39.9 & 0.140 \\
\hline CKD, n/N & 3 & $8 / 48$ & $13 / 124$ & 1.78 & $\begin{array}{l}{[0.66-} \\
4.84]\end{array}$ & 0.258 & 1.10 & 0.364 \\
\hline Immunosuppression, n/N & 3 & $5 / 36$ & $11 / 160$ & 2.93 & $\begin{array}{l}{[0.68-} \\
12.53]\end{array}$ & 0.148 & 26.50 & 0.256 \\
\hline \multicolumn{9}{|l|}{ Blood examination } \\
\hline WBC $\left(10^{9} / L\right)$, Mean $\pm S D$ & 3 & $9.74 \pm 1.07$ & $8.44 \pm 0.64$ & 1.63 & $\begin{array}{l}{[-0.60-} \\
3.85]\end{array}$ & 0.152 & 0.00 & 0.679 \\
\hline Neutrophil count $\left(10^{9} / \mathrm{L}\right)$, Mean \pm SD & 2 & $8.02 \pm 1.18$ & $6.69 \pm 0.60$ & 1.37 & $\begin{array}{l}{[-1.32-} \\
4.07]\end{array}$ & 0.318 & 12.30 & 0.286 \\
\hline Lymphocyte count $\left(10^{9} / \mathrm{L}\right)$, Mean $\pm S D$ & 2 & $0.75 \pm 0.06$ & $0.79 \pm 0.04$ & -0.04 & $\begin{array}{l}{[-0.19-} \\
0.12]\end{array}$ & 0.651 & 12.60 & 0.285 \\
\hline Creatinine $(\mu \mathrm{mol} / \mathrm{L})$, Mean $\pm S D$ & 4 & $127.94 \pm 13.13$ & $88.23 \pm 7.09$ & 33.32 & $\begin{array}{l}{[6.81-} \\
59.83]\end{array}$ & 0.014 & 0.00 & 0.739 \\
\hline $\mathrm{CRP}(\mathrm{mg} / \mathrm{L}), \mathrm{Mean} \pm \mathrm{SD}$ & 4 & $138.84 \pm 21.11$ & $173.95 \pm 22.01$ & -18.20 & $\begin{array}{l}{[-51.86-} \\
15.47]\end{array}$ & 0.289 & 0.00 & 0.539 \\
\hline LDH (IU/L), Mean $\pm S D$ & 2 & $561.01 \pm 171.56$ & $579.03 \pm 179.60$ & -5.81 & $\begin{array}{l}{[-67.70-} \\
56.08]\end{array}$ & 0.854 & 0.00 & 0.861 \\
\hline \multicolumn{9}{|c|}{ Respiratory sample characteristics in baseline } \\
\hline $\mathrm{PaO} 2 / \mathrm{FiO} 2$ & 6 & $118.44 \pm 21.06$ & $125.54 \pm 16.06$ & -1.72 & $\begin{array}{l}{[-14.90-} \\
11.46]\end{array}$ & 0.798 & 0.00 & 0.629 \\
\hline SAPS ॥ & 3 & $52.59 \pm 11.77$ & $40.87 \pm 1.15$ & 11.43 & $\begin{array}{l}{[-10.86-} \\
33.73]\end{array}$ & 0.315 & 75.10 & 0.018 \\
\hline SOFA & 4 & $7.38 \pm 2.84$ & $6.06 \pm 1.43$ & 1.36 & $\begin{array}{l}{[-0.12-} \\
2.88]\end{array}$ & 0.079 & 60.80 & 0.054 \\
\hline \multicolumn{9}{|l|}{ COVID-19 therapy } \\
\hline Lopinavir/ritonavir & 2 & $18 / 51$ & $37 / 160$ & 1.51 & $\begin{array}{l}{[0.68-} \\
3.37]\end{array}$ & 0.311 & 59.50 & 0.116 \\
\hline $\mathrm{HCQ}$ & 2 & $35 / 51$ & $96 / 160$ & 0.99 & $\begin{array}{l}{[0.89-} \\
1.10]\end{array}$ & 0.851 & 0.00 & 0.710 \\
\hline Azithromycin & 2 & $18 / 51$ & $48 / 112$ & 1.24 & $\begin{array}{l}0.41- \\
3.75\end{array}$ & 0.707 & 83.9 & 0.013 \\
\hline Corticosteroids & 8 & $41 / 100$ & 273/719 & 1.98 & $\begin{array}{l}{[1.08-} \\
3.63]\end{array}$ & 0.027 & 74.10 & $<0.001$ \\
\hline Tocilizumab & 4 & $33 / 72$ & $157 / 483$ & 1.43 & $\begin{array}{l}{[0.80-} \\
2.57]\end{array}$ & 0.233 & 70.50 & 0.017 \\
\hline
\end{tabular}

Page 10/12 


\begin{tabular}{|c|c|c|c|c|c|c|c|c|}
\hline Ventilated Prone & 2 & $27 / 41$ & $68 / 103$ & 1.16 & $\begin{array}{l}{[0.56-} \\
2.39]\end{array}$ & 0.692 & 77.4 & 0.036 \\
\hline ECMO & 2 & $4 / 28$ & $79 / 225$ & 0.77 & $\begin{array}{l}{[0.35-} \\
1.71]\end{array}$ & 0.517 & 0.00 & 0.567 \\
\hline RRT & 4 & $29 / 69$ & $90 / 319$ & 1.61 & $\begin{array}{l}{[1.04-} \\
2.50]\end{array}$ & 0.033 & 32.50 & 0.217 \\
\hline \multicolumn{9}{|l|}{ Outcome } \\
\hline Mortality, n/N & 11 & $65 / 127$ & $322 / 788$ & 1.66 & $\begin{array}{l}{[1.31-} \\
2.12]\end{array}$ & $<0.001$ & 22.50 & 0.229 \\
\hline Length of ICU stay (days), Mean \pm SD & 8 & $24.61 \pm 2.79$ & $20.80 \pm 1.75$ & 5.58 & $\begin{array}{l}{[-1.93-} \\
13.08]\end{array}$ & 0.145 & 68.50 & 0.002 \\
\hline
\end{tabular}

a, the field including only one study will not be pooled and shown; Abbreviation: CVD, Cardiovascular diseases; CKD, chronic kidney disease; RRT, Renal replacement therapy

\section{Figures}

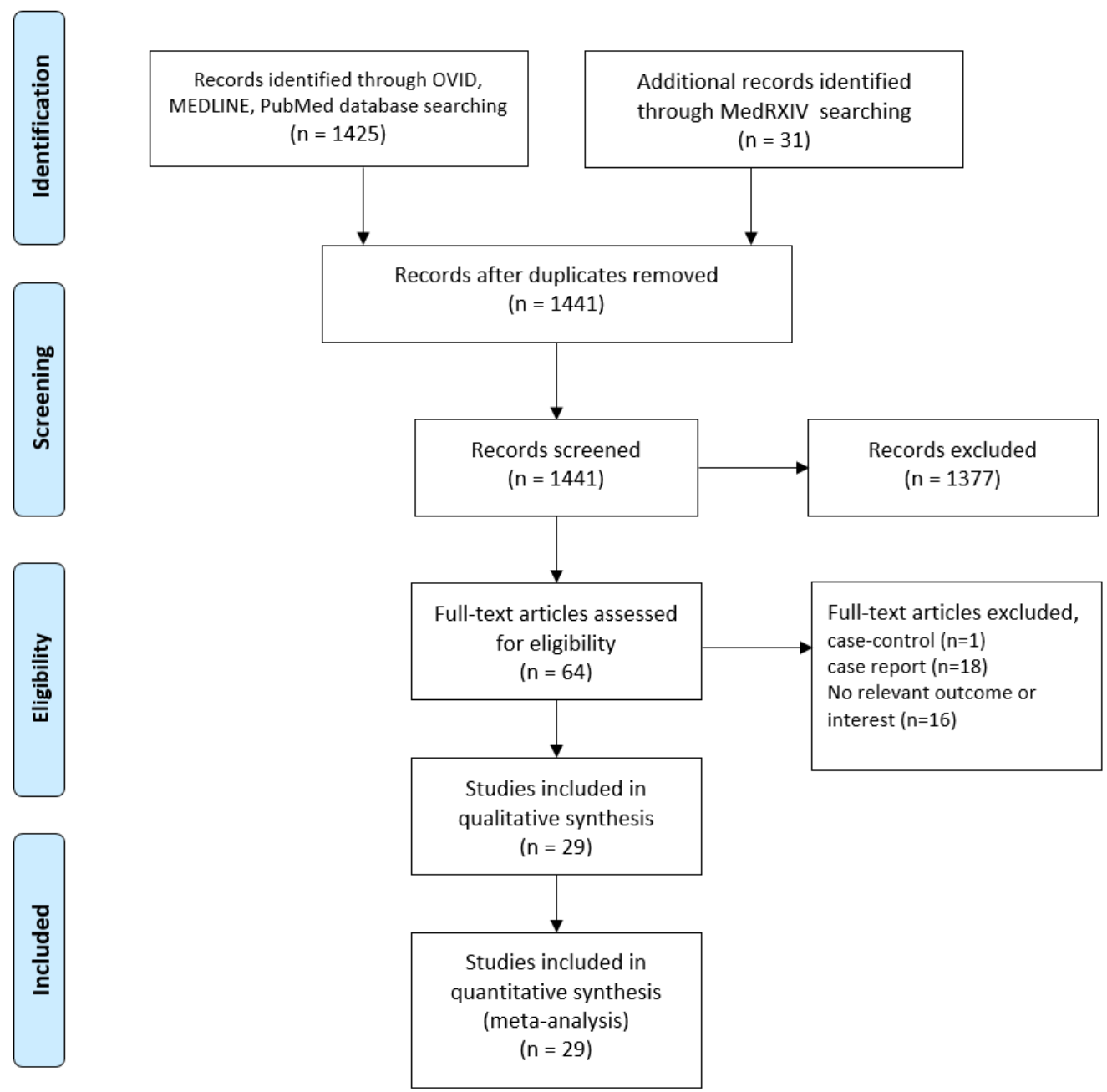

Figure 1

Flow Diagram of this study 
Author

Publication Year

Mean

Rutsaert L, et al. 2020

Nasir N, et al.

Bartoletti M, et al.

Mitaka $\mathrm{H}$,et al.

Dupont D, et al.

van Arkel ALE,et al.

van Grootveld $R$, et al.

White PL, et al.

2020

2020

2020

2020

2020

2020

2020

Roman-Montes CM,et al.

2020

Random effects model

Heterogeneity: $I^{2}=46 \%, \tau^{2}=3.055$
553, $p=0.07$

$\begin{array}{lllllll}-15 & -10 & -5 & 0 & 5 & 10 & 15\end{array}$

Weight

MRAW $95 \%-\mathrm{Cl}$ (random)

$8.42 \quad[4.87 ; 11.97] \quad 13.3 \%$

$5.60 \quad[0.60 ; 10.60] \quad 8.8 \%$

$4.71 \quad[3.04 ; 6.38] \quad 22.3 \%$

$7.15 \quad[1.68 ; 12.62] \quad 7.8 \%$

$5.28 \quad[2.40 ; 8.16] \quad 16.1 \%$

$10.25 \quad[2.78 ; 17.72] \quad 4.8 \%$

$10.25 \quad[5.24 ; 15.26] \quad 8.8 \%$

$12.75 \quad[7.13 ; 18.37] \quad 7.5 \%$

$8.14 \quad[3.82 ; 12.45] \quad 10.7 \%$

$7.28 \quad[5.48 ; 9.08] \quad 100.0 \%$

Figure 2

Time window of the patients developed CAPA
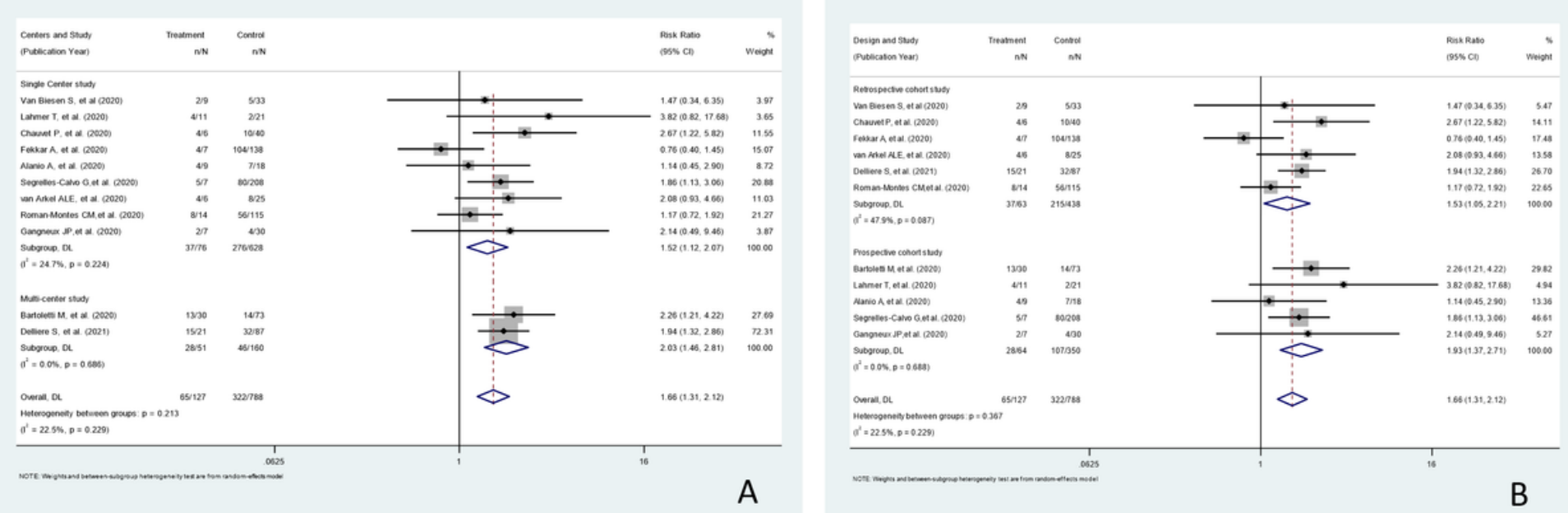

Figure 3

Comparison of the outcome of COVID-19 patients admitted to ICU with and Without CAPA A: Sub-group analysis by study design (Single Center or MultCenter); B: Sub-group analysis by study design (Prospective or Retrospective)

\section{Supplementary Files}

This is a list of supplementary files associated with this preprint. Click to download.

- Additionalfile1.docx 